\title{
The Scientific and Pseudoscientific Features of Smoking Cessation Products Which are Marketed on Internet
}

\author{
Bektas Murat YALCIN* \\ Department of Family Medicine, Faculty of Medicine, Ondokuz Mayis University, Samsun, Turkey
}

\begin{abstract}
Objective: Cigarette addiction is a common public health problem in Turkey. There may be people/institutions who want to abuse the desire of people who want to quit smoking. They may be marketing ineffective or placebo products without any real scientific and beneficial effects to individuals by making use of legal gaps. The aim of this study is to investigate the scientific value of cigarette products are sold online.

Method: We searched Internet search engines such as Google and Yandex, et al. with keywords such as "Stop Smoking" and "Smoking Cessation Products" in web-based marketing sites. In this context, 64 different cessation products were identified. We investigated these products according to a nine item scale which we designed eclectically. We also searched the evidence based scientific date about every product that we have found.

Results: These products can be grouped in three categories as electronic cigarette (e)-Cigarette (Not nicotine added) based $(n=15,23.4 \%)$, Herbal products $(n=37,57.8 \%$ ) and others (All of the non-classified products) $(n=12,18.7 \%)$. When the mean score that these groups which they get from the scale investigated it was seen that Herbal products got highest scores $(2.54 \pm 0.3)$ compared than the E-cigarette based $(1.21 \pm 0.8)$ and other non-classified products $(0.84 \pm 0.5)$ $(F=2.211, p=0,037)$. We have found only one evidence based scientific data (Level 3 Evidence) about 6 products (9.3\%) (All of them contains black nitter [Lavandula Stoechas]).
\end{abstract}

Conclusion: Our study revealed that there is very limited scientific evidence for the on-line marketed smoking cessation products.

Keywords

Smoking, Cessation, Pseudoscience, Internet, Web-based shopping

\section{Introduction}

With nearly 17 million daily smokers, smoking is a major health problem in Turkey [1]. Although there was a constant decrease in the adult smoking rates between 2007 to 2015, the latest data reveals that there is a rise in the adult smoking prevalence in Turkey [2]. Smoking has a devastating effect on physical health and also to the household incomes. Daily smokers consuming a package an of cigarette per day working for the lowest standard salary spend nearly $15 \%$ of their monthly income if only they buy cheapest cigarette brands on the market. Some life style modification treatments (smoking cessation and obesity) are provided free in primary care in Turkey through Healthy Life Centers administered by the Minister of Health. Also a free call line (call line 171) arranging appointments for smokers visiting these centers, including providing cessation phone consultations [3]. In some cases, the medical treatments (nicotine replacement therapy, Varenicline or Bupropion) are supplied free in these centers in limited amounts as these products are imported from abroad. However, many smokers may choose "over the counter products" which are offered as effective and a cheap therapy options for smoking cessation. These products mostly sold in web-based shopping sites or through other multimedia (television, internet etc.) resources. The scientific basis for these products are in debate and most likely they have pseudoscientific features and sold without proper authorization. Pseudoscience consists of statements, beliefs, or practices that are claimed to be both scientific and factual but are incompatible with the scientific method [4,5]. Pseudosci-

*Corresponding author: Prof. Bektas Murat YALCIN, Department of Family Medicine, Faculty of Medicine, Ondokuz Mayis University, Samsun, Turkey, Tel: 0362-3121919-3464, Fax: 03625-3122019

Accepted: December 07, 2020

Published online: December 09, 2020

Citation: YALCIN BM (2020) The Scientific and Pseudoscientific Features of Smoking Cessation Products Which are Marketed on Internet. Arch Fam Med Gen Pract 5(1):165-168 
Citation: YALCIN BM (2020) The Scientific and Pseudoscientific Features of Smoking Cessation Products Which are Marketed on Internet. Arch Fam Med Gen Pract 5(1):165-168

ence is often characterized by contradictory, exaggerated or unfalsifiable claims; reliance on confirmation bias rather than rigorous attempts at refutation; lack of openness to evaluation by other experts; absence of systematic practices when developing hypotheses; and continued adherence long after the pseudoscientific hypotheses have been experimentally discredited. Karl Popper explained the positivistic scientific method in detail. The term pseudoscience is considered pejorative [6] because it suggests something is being presented as science inaccurately or even deceptively.

The aim of this study is to investigate the scientific value of cigarette products are sold online.

\section{Material and Methods}

This is a descriptive and analytic study. The study is conducted through 1.9.2019 to 1.10.2019. We searched through main internet search engines (Google, Yahoo and Yandex) and with the keywords in Turkish;

- I want to quit smoking

- Stop smoking

- Products for quit smoking

- Help me quit smoking

We also searched popular internet shopping sites in Turkish market such as (Gittigidiyor.com, 11.N.com, Trendyol, and Cicek Sepeti.com etc.) with the same key words. We excluded the books, DVDs or other paid self-helping sites (A total of 112). We excluded all products related with NRT products or e-cigarettes $(n=24)$. All of the remaining products $(n=64)$ are investigated and rated according to a nine item scale. These rating items are accepted eclectically and pragmatically from a wide range of literature [7-11]. These items were stated as most common criteria's which are common in pseudoscientific products according to these data. Each item is rated as 1 is it meets the criteria and 0 if not. At the end all of the items are summed and a general product score is obtained. The increasing score of each item from this scale is accepted as increase in the products safety and scientific value. The items of the scale are stated below;

- Is the product's scientific principle or basis for helping to quit smoking explained?

- Is there any scientific data presented about the success rate of smoking cessation the product in the site?

- Is there any warning or mention about the side effects of the product?

- Is there a real money back warranty?

- Is the address or the identity of company of the product is provided and confirmed in the site?

- Is there any confirmed communication information (Web, GSM etc.) of the company?

- Is the company referring to any scientific research of respected scientists or researchers?

- Do the product claims about the effectiveness mostly rely on scientific data rather than on previous consumer testimonials (Before and after photos etc.) in the site?

- Is there any legal safety certification of any kind (Ministry of Health or Ministry of Agriculture)?

Last of all we evaluated each product according the Scottish Intercollegiate Guidelines Network (SIGN) 50 criteria [12]. SIGN 50 criteria determine the scientific evidence level of any information emerging on a medical subject and the hierarchical level of evidence. Accordingly, it provides recommendations to health professionals on certain issues. For instance, high quality meta-analyses are accepted as 1++ evidence level.

\section{The statistical methods}

All of the data is upload to SPSS Version 16.0. A p value of $<0.05$ is accepted a statistically significant. The mean scores of each product group (Herbal, E-cigarette and others) are accepted as independent variables. The relation between these three group is investigated with One-Way ANOVA test.

\section{Results}

We identified 64 different products with different names and different companies. These products can be grouped in three categories as E-Cigarette (Not nicotine added) based ( $n=15,23.4 \%)$, Herbal products $(n=37,57.8 \%$ ) and others (All of the non-classified products) ( $n=12,18.7 \%$ ). The total mean score of these products according to our scale was $1.86 \pm 0.75$ ( $\min =0, \max =3$ ). Herbal products received a total score of $2.54 \pm 0.3$ from our scale while E-cigarette based products received a total score of $1.21 \pm 0.8$. Others received a total score of $0.84 \pm 0.5$ from our scale.

- The positive scores of different products from the items of the scale we prepared are presented at Table 1.

Only in one study we found scientific data about the black nitter (Lavandula Stoechas) in the web search. Six different products (9.3\%) in the herbal products group which contains black nitter (Lavandula Stoechas) are accepted to have evidence-based scientific data (Level 3 Evidence).

We accepted the total scores of the scale which we prepared to evaluate the smoking cessation products' scientific value that are marketed on the internet as independent variables for One-Way ANOVA test. The mean scores of the three groups are compared with each other with this test. Herbal products received higher scores from our test compared than the others $(F=2.211, p=0.037)$. The multiple comparisons between different products based on One-Way ANOVA test is presented at Table 2.

\section{Discussion}

Our study revealed that there is no scientific data about the products which are marketed online. When all products marketed for smoking cessation are examined over the internet, herbal remedies are particularly remarkable. There are three main types of cessation products offered through internet/Web/Multimedia shopping. These are E-Cigarette based 
Citation: YALCIN BM (2020) The Scientific and Pseudoscientific Features of Smoking Cessation Products Which are Marketed on Internet. Arch Fam Med Gen Pract 5(1):165-168

Table 1: The positive scores of different products from the items of the scale that is prepared.

\begin{tabular}{|c|c|c|c|c|}
\hline \multirow[t]{3}{*}{ Items } & \multicolumn{4}{|c|}{ The group of the products marketed in internet } \\
\hline & $\begin{array}{l}\text { Herbal } \\
(n=37)\end{array}$ & $\begin{array}{l}\text { E-Cig }{ }^{*} \\
(n=15)\end{array}$ & $\begin{array}{l}\text { Others } \\
(n=12)\end{array}$ & $\begin{array}{l}\text { Total } \\
(n=64)\end{array}$ \\
\hline & $\mathbf{N}, \%$ & $\mathbf{N}, \%$ & $\mathbf{N}, \%$ & $\mathrm{~N}, \%$ \\
\hline Is the product's principle for helping people to quit smoking explained? & 6, 9.3 & 4, 5.9 & 2, 3.1 & $12,18.75$ \\
\hline $\begin{array}{l}\text { Is there any scientific data presented about the success rate of smoking cessation } \\
\text { the product in the site? }\end{array}$ & 0,0 & 0,0 & 0,0 & 0, \\
\hline Is there any warring or mention about the side effects of the product? & $1,1.5$ & $1,1.5$ & $0,0.0$ & 2, 3.1 \\
\hline Is there a real money back warranty? & $6,6.9$ & 0,0 & $10,15.6$ & $16,25.0$ \\
\hline $\begin{array}{l}\text { Is the address or the identity of cooperation of the product is provided and } \\
\text { confirmed in the site? }\end{array}$ & $4,5,9$ & 6, 6.99 & 4, 5.9 & $14,21.8$ \\
\hline $\begin{array}{l}\text { Is there any confirmed communication information (Web, GSM etc.) of the } \\
\text { company }\end{array}$ & $9,14.0$ & $11,17.1$ & $7,10.9$ & $27,42.1$ \\
\hline $\begin{array}{l}\text { Is the company referring any scientific research of respected scientists or } \\
\text { researchers? }\end{array}$ & $2,3.1$ & 0,0 & 0,0 & $2,3.1$ \\
\hline $\begin{array}{l}\text { Do the product claims about the effectiveness mostly rely on scientific data rather } \\
\text { than on previous consumer testimonials (Before and after photos etc.) in the site? }\end{array}$ & $4,5,9$ & 0,0 & 0,0 & $4(6.2)$ \\
\hline $\begin{array}{l}\text { Is there any legal safety certification of any kind (Ministry of Health or Ministry of } \\
\text { Agriculture)? }\end{array}$ & 0,0 & 0,0 & 0,0 & 0,0 \\
\hline
\end{tabular}

Table 2: The multiple comparisons between different products which are marketed in internet according to their mean score from the scale*.

\begin{tabular}{|l|l|l|l|l|l|}
\hline Dependent Variable & Mean Difference & & Sig & \multicolumn{2}{l|}{$95 \% \mathrm{Cl}$} \\
\hline & & & & Lower Bound & Upper Bound \\
\hline E-Cig ${ }^{\ddagger}$ vs. Herbal & -1.338 & 0,823 & 0.038 & -1.312 & $-0,841$ \\
\hline E-Cig vs. Others & 0.372 & 0.021 & 0.910 & 0.402 & 0.657 \\
\hline Herbal vs. Others & 1.714 & 1.024 & 0.021 & 1.639 & 2.027 \\
\hline ₹E-Cigarette & & & & \\
\hline *One-Way ANOVA test is used & & & & \\
\hline
\end{tabular}

products which do not contain any nicotine. These non-nicotine content e-cigarettes claim that they use different flavors (Water Peppermint, clove) to help people quit. While using it like a cigarette the marketers claim that the product is three times more effective than using no special cessation method. However, we failed to find any evidence based knowledge to confirm these claims.

The product group classified as "Other" included several different items. In this group there are bio-magnetic magnets and aromatherapy products. Acupuncture magnetic smoking cessation earnings/rings are claimed as bio-magnetic magnets. In some web sites they are advised to be used three or four hours a day, preferably in the morning. Also some other company's web-sites they are advised that the same device be worn in the ear for several hours in the afternoon and in the evening. The producers/importers of the product claimed that it cures the electromagnetic aura of the smokers although they contradict each other in the practice of the same products. Aromatherapy products are to be sniffed at the time of the nicotine cravings after cessation period. Many smokers who tries to quit smoking, may experience very severe nicotine craving episodes especially in the early period when their blood nicotine levels drop. Some of these ex-smokers start to smoke again because of the severity of these cravings $[13,14]$. It is claimed that these products decrease or nullify the nicotine cravings. We also failed to find any evidence based knowledge to confirm these claims.

Lastly Herbal products was the largest group of products. Most of these products include different herbal recipes. Most common herbal products were; Clove, Black Nettle, Licorice, Bay Seed, Lemon Balm, Oat, Water Peppermint, Bitter Yavsan, Ginger, Nigella and pollen. We have noticed that several different products might contain the same items in different combinations. Although the names of the products change, two important ingredients are included in these products. One of these substance is clove (Syzygium aromaticum). Cigarettes made from fully clove is very popular in India and South East Asia. Clove-flavored cigarettes are called as Kretek and they are made from a combination of tobacco and ground-clove mixed with a sauce, smoked widely in Indonesia. However, there is very strong evidence that cloved floured nicotine products (cigarette or hookah) increases rate of dependency 
Citation: YALCIN BM (2020) The Scientific and Pseudoscientific Features of Smoking Cessation Products Which are Marketed on Internet. Arch Fam Med Gen Pract 5(1):165-168

[15]. The second substance is black nitter (Lavandula stoechas). This is a mediterrian flora plant. It is commonly used in many herbal products. There are some claims that using black nitter while smoking causes mild nausea. Only in a master thesis it was discussed that it bonds with nicotinic receptors in molecular level [6]. This study is not published yet and it provides a small data about the pharmacodynamics of how the black nitter can help for smoking cessation. According to SIGN 50 criteria non-analytic studies (case reports, qualitative research and laboratory studies) are accepted to have evidence level 3 . This is a low place in evidence hierarchy. Based on this study we accepted that $6(9.3 \%)$ products which contains black nitter (Lavandula stoechas) have evidence based level 3. This study might have promising scientific basis for using black nitter for smoking cessation. However, we failed to find any research which investigates the cessation rates or side effects of smokers who use black nitter. Further research is needed to discuss about the effectivity of black nitter until than it is not advisable to recommend smokers to use it.

There are also dangerous products among this group as a product is depending on almond paste. This product claims that it repairs lungs and all of the tar accumulated in lungs by years vanishes after regular use. The producers of this product is now sued as risking the health of people by cyanide poisoning risk.

When we investigated the mean scores of items from our scale we have noticed that the highest ranking item was "Is there any confirmed communication information of the company" with $42.1 \%$ ( $n=27$ ). In order to make a sale through a general internet trade site (Tendyol, Gitti Gidiyor etc.) you have to register a company name. Not surprisingly, we failed to find any valid communication information for the company in individual product sale sites. This situation can be explained with the trading policies and laws dictate internet shopping. In registered internet trading sites every product offered to sale is taxed which makes a necessity of registry of these companies. The items which had the lowest scores were "Is there any scientific data presented about the success rate of smoking cessation the product in the site" and the "Is there any legal safety certification of any kind". First we failed to find any kind of legal certifications of safety for these products. Although two herbal and one E-cigarette products claimed ratios about cessation success rates no scientific research has been referenced that can confirm these rates.

Our study has several limitations. First of all, we designed the scale that we used in this study. We failed to find any scales to evaluate the products that we are investigating in our study so we were forced to use an eclectic approach to evaluate the safety and scientific value of the over the counter products which are marketed on line. So our results de- pending on this scale are highly skeptical. However, we also search every product with the principles of evidence based medicine in order to overcome this problem.

Our study is revealed that there is no scientific evidence for any internet based products for smoking cessation in Turkey which is included in our research. Without any real scientific data these products may be classified as pseudoscientific products and primary care physicians must avoid encouraging their patients to use them for smoking cessation. As primary care physicians it is useful to have knowledge about these kind of products, using advantages of gaps in the law in order to inform their patients.

\section{References}

1. Bilir N (2010) Dünyada ve Türkiye'de tütün kullanımı epidemiyolojisi, Tütün tütün kontrolü içinde, sayfa. Toraks Derneği Yayını, 21-35.

2. Bilir N, Çakır B, Dağlı E, et al. (2009) Tobacco control in Turkey, WHO Euro Copenhagen.

3. I want to quit smoking. Smoke Free Air, Alo171.

4. Pseudoscience. Wikipedia.

5. Cover JA, Curd M (1998) Philosophy of science: The central issues. WorldCat 1-82.

6. Popper Karl (1962) Conjectures and refutations. The growth of scientific knowledge. Basic Books, New York.

7. Hurd PD (1998) Scientific literacy: New minds for a changing world. Science Education 82: 407-416.

8. Martin M (1994) Pseudoscience, the paranormal, and science education. Science \& Education 3: 1573-1901.

9. Makgoba MW (2002) Politics, the media and science in HIV/ AIDS: The peril of pseudoscience. Vaccine 20: 1899-1904.

10. Bauer HH (2000) Science or pseudoscience: Magnetic healing, psychic phenomena, and other heterodoxies. University of IIlinois Press.

11. Alcock J (2001) Science vs. pseudoscience, nonscience, and nonsense. The Skeptical Inquirer 25: 50-54.

12. (2011) SIGN 50 a guideline developer's handbook. Scottish Intercollegiative Network.

13. Palipudi K, Mbulo L, Kosen S, et al. (2015) A cross sectional study of kretek smoking in Indonesia as a major risk to public health. Asian Pac J Cancer Prev 16: 6883-6888.

14. Wray JM, Gass JC, Tiffany ST (2013) A systematic review of the relationships between craving and smoking cessation. Nicotine Tob Res 15: 1167-1182.

15. Hajiyeva K (2018) Design of nicotinic acetylcholine antagonists with virtual ligand scanning method. Unpublished Master Thesis, Hacettepe University, Department of Chemistry.

DOI: $10.36959 / 577 / 499$

Copyright: (C) 2020 YALCIN BM. This is an open-access article distributed under the terms of the Creative Commons Attribution License, which permits unrestricted use, distribution, and reproduction in any medium, provided the original author and source are credited. 